\title{
Teaching
Methods
}

\section{Assessing Student Learning From an Experiential Module in a Greenhouse Management Course Using Hydroponics and Recirculating Solution Culture}

\author{
Joshua K. Craver ${ }^{1}$ and Kimberly A. Williams ${ }^{2,3}$
}

AdDitional INDEx words. Bloom's taxonomy, higher-order learning, laboratory exercise, lower-order learning, nutrient film technique

SUMMARY. Student learning from producing crops in recirculating culture for a 6-week module in the Fall 2013 course HORT 570 Greenhouse Operations Management at Kansas State University was assessed. The module design followed Kolb's experiential learning model, with teams of students responsible for production of lettuce (Lactuca sativa 'Green Oak Leaf') or basil (Ocimum basilicum 'Italian Large Leaf') and chives (Allium schoenoprasum 'Purly') crops in either a nutrient film technique (NFT) or in-pot recirculating culture system. Goals were to discern if this class experience would 1) improve student confidence and understanding of not only recirculating solution culture systems, but also general crop nutrient management; and 2) improve higher-order learning (HOL) skills of applying, analyzing, and evaluating information. Student learning was evaluated by administering the same survey, which included questions to evaluate student perception, lower-order learning (LOL), and HOL, at four separate times during the semester: 1) before mentioning plant nutrition, hydroponics, or recirculating solution culture; 2) after plant nutrition lectures but before the experiential module; 3 ) immediately upon completion of the experiential module; and 4) at the end of the semester. An increase in student confidence related to managing crop production in recirculating solution culture and nutrient management was perceived by students upon completion of the module. A significant increase in LOL occurred after the material was presented during the course lectures with an increase also occurring upon completion of the experiential module. In contrast, HOL did not significantly increase after the lecture material was presented, but significantly increased upon completion of the module. Both LOL and HOL was retained at the end of the semester. This evidence supports the role of experiential learning in improving student understanding and fostering HOL.

A $\mathrm{n}$ increasing number of greenhouse growers are producing food crops using various types of recirculating solution culture. With nationwide trends toward local, sustainable, and/or organic food production (e.g., Dimitri and Greene, 2012), the greenhouse industry is shifting away from solely producing herbaceous ornamental crops and integrating or replacing these crops with vegetables and herbs. For this reason, hydroponics and other systems using recirculated nutrient solution have become an increasingly important topic for many greenhouse production courses.

Nutrient management in hydroponic production systems is more intensive than a typical production scenario because the grower must more closely manage all macro- and micronutrients for the crop. Additionally, because hydroponic nutrient solutions are unbuffered (i.e., compared with soils), $\mathrm{pH}$ can change dramatically over a 24 -h period based on what nitrogen forms are supplied and levels of microbial activity in the solution. With these challenges in mind, the incorporation of a module where crops are produced in recirculating solution provides a means to put the knowledge students have gained from previous plant science courses to practice and hone plant nutrient management skills.

In an academic environment, the focus of a course is frequently on the recognition and recall of information presented by the instructor (Krathwohl, 2002). However, the understanding and use of knowledge is often considered a more important objective. In his revision of Bloom's taxonomy, Krathwohl (2002) stated that higher cognitive processes, such as evaluating and creating, are often considered the more important and long-lasting fruits of education. Cannon and Feinstein (2005) furthered this idea as they divided Bloom's taxonomy into different levels. They proposed that lower levels involved more knowledge and content-related objectives, whereas higher levels delved into more cognitive skills and processes. These authors further discussed one of the strong arguments for experiential learning is that it places students in real situations where they must not only call on lower-level concepts, but also engage in higher levels of learning as they "analyze what is going on in the game or exercise, synthesize solutions to address the situation,

\begin{tabular}{llll}
\hline $\begin{array}{l}\text { Units } \\
\begin{array}{l}\text { To convert U.S. to SI, } \\
\text { multiply by }\end{array}\end{array}$ & U.S. unit & SI unit & $\begin{array}{l}\text { To convert SI to U.S., } \\
\text { multiply by }\end{array}$ \\
\hline 29.5735 & $\mathrm{fl} \mathrm{oz}$ & $\mathrm{mL}$ & 0.0338 \\
3.7854 & gal & $\mathrm{L}$ & 0.2642 \\
1 & $\mathrm{meq} / \mathrm{L}$ & $\mathrm{mmol} \cdot \mathrm{L}^{-1}$ & 1 \\
1 & $\mathrm{mmho} / \mathrm{cm}$ & $\mathrm{dS} \cdot \mathrm{m}^{-1}$ & 1 \\
1 & $\mathrm{ppm}$ & $\mathrm{mg} \cdot \mathrm{L}^{-1}$ & 1
\end{tabular}


and evaluate their relative merits" (Cannon and Feinstein, 2005).

Kolb (1984) addressed experiential learning theory as a "holistic integrative perspective on learning that combines experience, perception, cognition, and behavior." Kolb further proposed an experiential learning model where students engage in a concrete experience, reflective observation, abstract conceptualization, and active experimentation. This holistic perspective of teaching has been practiced in many horticulture scenarios. One such instance was the hands-on integration of sustainable design through the construction of an exhibit at a trade show for landscape architecture and horticulture students at Temple University (Lamba and Chapman, 2010); another was the installation of a residential irrigation system in an undergraduate landscape irrigation course (Lavis and Brannon, 2010). Scenarios such as these provide students with realworld experiences as well as foster an environment where the learning model proposed by Kolb can be put into practice.

The idea of establishing an experiential learning module involving recirculating solution culture stems from a desire to incorporate these higher levels of learning into a typical greenhouse management course. Additionally, by incorporating these systems into the course, students would become familiar with these production systems while also gaining an increased understanding of the pros and cons involved with them. With plants produced in hydroponics being rapidly responsive to management decisions, hands-on experience provides the students with the opportunity to evaluate and address firsthand critical nutrient management concepts,

Department of Horticulture, Forestry, and Recreation Resources, Kansas State University, Manhattan, KS 66506

This manuscript has been assigned Contribution no. 14-418-J by the Kansas Agricultural Experiment Station (KAES). This research was funded by Kansas State University's College of Agriculture Innovations in Teaching, Learning and Assessment Mini-Grant Program.

Mention of a trademark, proprietary product, or vendor does not constitute a guarantee or warranty of the product by the U.S. Dept. of Agriculture and does not imply its approval to the exclusion of other products or vendors that also may be suitable.

${ }^{1}$ Graduate Teaching Assistant

${ }^{2}$ Professor and University Distinguished Teaching Scholar

${ }^{3}$ Corresponding author. E-mail: kwilliam@ksu.edu. such as the role of nitrogen form in $\mathrm{pH}$ changes.

Our hypothesis was that by integrating a hands-on, 6-week module involving hydroponics and recirculating solution culture into the HORT 570 Greenhouse Operations Management laboratory at Kansas State University, multiple facets of student learning would be improved. Specifically, we wanted to discern if this added class experience would l) improve student confidence and understanding of not only recirculating solution culture systems but also general crop nutrient management; and 2) improve higher-order thinking skills of applying, analyzing, and evaluating information (Krathwohl, 2002). With these goals in mind, the objectives of this study were to 1 ) measure change in student confidence to manage crops produced in recirculating solution culture from participation in the experiential module; 2 ) determine whether the module improved student mastery of general plant nutrient management content not specific to hydroponic production; and 3 ) assess the module impact on LOL vs. HOL.

\section{Materials and methods}

During the first laboratory of the course, students were arranged into eight teams of five ( $\mathrm{N}=40$ students) for various projects and activities throughout the semester. Following is a breakdown of their majors: 23 Horticulture (13 Greenhouse and Nursery Management, six Landscape Design, two Fruit and Vegetable Production, and two Horticultural Science), 13 Agricultural Education, one Agronomy, and one Animal Sciences and Industry; two students were majoring in a Business degree. One of these projects was a hydroponics module requiring each team of students to maintain two recirculating solution culture systems, one using conventional fertilizers and the other using organic, for a 6 -week period. The use of teams required students to communicate regularly in regard to scheduling and problem solving. This goal of peer interaction within teams is similar to the on-site instruction conducted by Stearns (1995) for landscape contracting students. Two different types of recirculating solution culture systems were used. Two teams were given a NFT system
(CropKing, Lodi, OH) in which they produced 'Green Oak Leaf' lettuce. The other six teams used in-pot recirculating culture systems (CropKing) to produce 'Italian Large Leaf' basil and 'Purly' chives. Both NFT and inpot systems were used to expose students to different methods of recirculating culture. On the first day of the module, each team was required to construct their systems with the materials provided in the laboratory. Construction was straightforward and included pump and hose positioning, placing plants or pots within the system, and adjusting the system placement to address leaks. Students were then tasked with making all management decisions Monday through Friday for their assigned production systems, with adjustments over the weekend made by the course teaching assistant as necessary. Responsibilities included 1) adding water daily to maintain a system volume of $80 \mathrm{~L} ; 2$ ) recording daily $\mathrm{pH}$ and electrical conductivity (EC) measurements in a weekly log; 3 ) maintaining a target $\mathrm{pH}$ of 5.5 to 7.0 by applying either a dilute base or acid, as needed; and 4) maintaining a target EC by applying fertilizer as needed. Each team was given separate instructions for maintaining their conventional and organic hydroponic systems. Each student was required to accomplish and $\log \mathrm{pH}$ and EC measurements as well as any adjustments made to their team's systems at least once per week. Students were given an individual laboratory grade based on their participation in the weekly activities. To obtain daily measurements for $\mathrm{pH}$ and $\mathrm{EC}$, each team was given a $\mathrm{pH}$ and $\mathrm{EC}$ Combo meter (Hanna Instruments, Woonsocket, RI).

EC maintenance. Conventional systems were fertilized with $150 \mathrm{mg} \cdot \mathrm{L}^{-1}$ nitrogen using either a combination of $5 \mathrm{~N}-5.2 \mathrm{P}-21.6 \mathrm{~K}$ (Jack's Classic Hydroponic 5-12-26; JR Peters, Allentown, PA), calcium nitrate, and Epsom salts, or 16N-1.7P-14.1 K(Jack's Classic HydroFeED 16-4-17, JR Peters). A target EC level for the conventional systems was calculated by each team on the first day of the module with the following instruction: when EC drops to two-thirds of the starting EC, add one-third batch of fertilizer. These one-third batches of fertilizer were measured out weekly by support staff for the students to apply as needed. 
Organic systems were fertilized with $150 \mathrm{mg} \cdot \mathrm{L}^{-1} \mathrm{~N}$ using one of the following: $5 \mathrm{~N}-0.4 \mathrm{P}-0.8 \mathrm{~K}$ (Fertilome Fish Emulsion Fertilizer 5-1-1; Voluntary Purchasing Groups, Bonham, TX), 6N-1.7P-2.5K (Pura Vida 6-43; Technaflora Plant Products, Port Coquitlam, BC, Canada), 4N-1.7P$0.8 \mathrm{~K}$ (Drammatic “One" 4-4-1; Dramm Corp., Manitowoc, WI), or $2 \mathrm{~N}-2.2 \mathrm{P}-0.8 \mathrm{~K}$ (Drammatic "K" 2$5-1$, Dramm Corp.). Additionally, 2N-0P-5K (Verdanta ${ }^{\mathrm{TM}}$ PL-2 2-06; BioWorks, Victor, NY) was added during fertilizer applications to supplement potassium as needed. Because EC is not as well correlated to total essential nutrient content when organic fertilizers are used, students were given different management instructions for their organic systems regarding $\mathrm{EC}$ on the first day of the module: when EC drops below $1.5 \mathrm{dS} \cdot \mathrm{m}^{-1}$, add one-third volume of full-strength fertilizer.

pH MaInTENANCE. Adjustments to $\mathrm{pH}$ were made using a separate dilute acid and base for conventional and organic systems. For the conventional systems, $1 \mathrm{~N}$ sulfuric acid $\left(\mathrm{H}_{2} \mathrm{SO}_{4}\right)$ was used to lower $\mathrm{pH}$, while $0.1 \mathrm{~N}$ sodium hydroxide $(\mathrm{NaOH})$ was used to raise it. For the organic systems, OMRI-certified materials of SaferGro ${ }^{\circledR} \mathrm{pH}$ Down $^{\circledR}(40 \%$ Bhydroxytribarallylic acid; JH Biotech, Ventura, CA) was used to lower the
pH, while SaferGro ${ }^{\circledR} \operatorname{Humax}^{\circledR}($ humic acids derived from leonardite, $\mathrm{JH}$ Biotech) was used to raise it. Teams were tasked with making these adjustments by applying the appropriate solution $3 \mathrm{~mL}$ at a time until the target $\mathrm{pH}$ was achieved.

Assessment. Module efficacy was measured from individual student responses to a survey instrument (Tables 1-3). This same survey was administered at four separate time intervals during the semester: Time 1 [before mentioning plant nutrition, hydroponics, or recirculating solution culture during the course (11 Sept. 2013)], Time 2 [after the plant nutrition lectures were delivered but before the initiation of the module (2 Oct. 2013)], Time 3 [immediately upon completion of the module (13 Nov. 2013)], and Time 4 [at the end of the semester during the final examination (20 Dec. 2013)]. Nutrient management topics covered in lectures between Time 1 and Time 2 included: review of essential plant nutrients, preplant nutrient additions, formulating fertilizer programs, effect of nitrogen form on root medium $\mathrm{pH}$ and plant growth, soluble and slowrelease fertilizers, and corrective procedures for $\mathrm{pH}$ and $\mathrm{EC}$ outside of optimal ranges.

The first section of this survey consisted of six perception questions concerning the students' confidence with various aspects of greenhouse production and plant nutrition (Table $1)$. The second section of this instrument contained eight LOL questions (Table 2) and seven HOL questions (Table 3). Questions were classified as either LOL or HOL based on Krathwohl's revised Bloom's taxonomy (Krathwohl, 2002). For the purpose of this study, LOL-based questions focused on the cognitive processes of remembering and understanding, while the HOL-based questions focused on applying, analyzing, and evaluating information. These questions were used to evaluate changes in student knowledge over the course of the semester. Students were not debriefed about correct answers to the LOL or HOL questions, nor did they learn whether their responses were correct after completing the survey at any time.

To evaluate overall changes in LOL and HOL, an index for each type of learning was created. These indexes were based on the number of correct answers out of seven total questions for each type of learning. For the LOL index, questions 1 to 7 from Table 2 were included. For the HOL index, questions 1 to 7 from Table 3 were included. For both indexes, averages were then aggregated from all students for each time point. For student responses to be included in each of these evaluations, two

Table 1. Average HORT 570 Greenhouse Operations Management student responses to perception questions over four time periods: Time 1 [before mentioning plant nutrition, hydroponics, or recirculating solution culture during the course (11 Sept. 2013)], Time 2 [after the plant nutrition lectures were delivered but before the initiation of the module (2 Oct. 2013)], Time 3 [immediately upon completion of the module (13 Nov. 2013)], and Time 4 [at the end of the semester during the final examination (20 Dec. 2013)]. Questions addressed student confidence and perception across various areas of greenhouse production, hydroponic production, and general plant nutrition.

\begin{tabular}{|c|c|c|c|c|}
\hline \multirow[b]{2}{*}{ Perception question } & \multicolumn{4}{|c|}{ Avg student response $(1-6 \text { scale })^{\mathrm{z}}$} \\
\hline & Time 1 & Time 2 & Time 3 & Time 4 \\
\hline $\begin{array}{l}\text { 1) I am confident that I can successfully produce a potted } \\
\text { crop in a greenhouse production system. }\end{array}$ & $4.8 c^{y}$ & $5.1 \mathrm{bc}$ & $5.4 \mathrm{ab}$ & $5.5 \mathrm{a}^{\mathrm{x}}$ \\
\hline $\begin{array}{l}\text { 2) I am confident that I can successfully produce } \\
\text { a crop using a hydroponic system. }\end{array}$ & $3.3 \mathrm{~b}$ & $3.5 \mathrm{~b}$ & $5.5 \mathrm{a}$ & $5.4 \mathrm{a}$ \\
\hline $\begin{array}{l}\text { 3) I understand the pros and cons of using conventional fertilization } \\
\text { programs vs. organic fertilization programs. }\end{array}$ & $3.7 \mathrm{~b}$ & $4.2 \mathrm{~b}$ & $5.3 \mathrm{a}$ & $5.3 \mathrm{a}$ \\
\hline $\begin{array}{l}5 \text { ) I believe that producing crops hydroponically is an effective alternative to } \\
\text { traditional production systems. }\end{array}$ & $4.5 \mathrm{NS}$ & $4.5 \mathrm{NS}$ & $4.6 \mathrm{NS}$ & $4.5 \mathrm{Ns}$ \\
\hline $\begin{array}{l}\text { 6) I believe that understanding how to use and manage a hydroponic system } \\
\text { will be beneficial to me if my future career includes crop production. }\end{array}$ & $5.2 \mathrm{NS}$ & $5.0 \mathrm{NS}$ & $5.2 \mathrm{NS}$ & $5.3 \mathrm{NS}$ \\
\hline
\end{tabular}

${ }^{2}$ Likert scale: 1 = strongly disagree, $2=$ disagree, $3=$ somewhat disagree, 4 = somewhat agree, $5=$ agree, and $6=$ strongly agree

yAverages for each question were obtained from a total of $\mathrm{N}=33$ responses for each time period.

${ }^{x}$ Different letters indicate that means are significantly different based on multiple comparisons at $\alpha=0.05$ using the Bonferroni adjustment; Ns indicates no significant difference between means. 
Table 2. Average percent correct HORT 570 Greenhouse Operations Management student responses to eight lower-order learning (LOL) multiple choice questions concerning hydroponic production and general plant nutrition over four time periods: Time 1 [before mentioning plant nutrition, hydroponics, or recirculating solution culture during the course (11 Sept. 2013)], Time 2 [after the plant nutrition lectures were delivered but before the initiation of the module (2 Oct. 2013)], Time 3 [immediately upon completion of the module (13 Nov. 2013)], and Time 4 [at the end of the semester during the final examination (20 Dec. 2013)]. Correct answers to each question are in bold.

\section{LOL knowledge question ${ }^{\mathrm{z}}$}

1) As $\mathrm{pH}$ of a root medium becomes more acidic, the $\mathrm{pH}$ value [increases or decreases]. (Circle one)

2) When nitrogen only in the nitrate $\left(\mathrm{NO}^{3-}\right)$ form is applied to a crop in a fertilizer solution and then taken up by plants, over time $\mathrm{pH}$ will: (Circle one)

a. Increase

b. Decrease

c. Nitrogen form does not influence $\mathrm{pH}$

3) Low oxygen levels in hydroponics systems... (Circle one)

a. ...do not need to be managed because oxygen is not necessary for root function b. ... should be increased using air stones or other procedures because low oxygen can limit plant growth

c. ....are associated with low electrical conductivity (EC) levels in recirculating solution

4) $\mathrm{pH}$ is least stable over time in... (Circle one)

a. ... a recirculating solution of a hydroponic system to which inorganic fertilizer salts are being added

b. ... a recirculating solution of a hydroponic system to which liquid organic fertilizers are being added

c. ...the root medium of a potted crop in a recirculating system to which conventional, slow-release fertilizers were incorporated pre-plant

5 ) If the root medium in which crops are sown for hydroponic production is oasis medium or rockwool, all micronutrients must be added to the recirculating solution. (Circle one)

a. True, because the root medium does not contribute any micronutrients to the crop

b. False, because the root medium provides some iron and other trace elements for the crop

c. Doesn't matter, because adequate levels of micronutrients are found in most water sources

6) Which two essential plant nutrients should you take care to keep separate when preparing concentrated fertilizer solutions? Circle one.

a. calcium and nitrate

b. calcium and phosphate

c. nitrate and phosphate

7) What do the three numbers in the fertilizer formulation 20-10-20 represent?

(Circle one)

a. \% nitrogen $(\mathrm{N})-\%$ phosphorus $(\mathrm{P})-\%$ potassium $(\mathrm{K})$

b. ppm N-ppm P-ppm K

c. $\% \mathrm{~N}-\% \mathrm{P}_{2} \mathrm{O}_{5}-\% \mathrm{~K}_{2} \mathrm{O}$

d. \% calcium $(\mathrm{Ca})-\%$ magnesium $(\mathrm{Mg})-\%$ carbonate

e. ppm Ca-ppm $\mathrm{Mg}$-ppm carbonate

f. \% calcium oxide $(\mathrm{CaO})-\%$ magnesium oxide $(\mathrm{MgO})-\%$ carbonic acid $\left(\mathrm{H}_{2} \mathrm{CO}_{3}\right)$

8 ) Indicate which of the following elements are essential for plant growth and development (Circle all correct).
a. aluminum
g. copper
b. boron
h. fluoride
c. calcium
i. hydrogen
d. carbon
j. iron
e. cesium
k. lithium
m. manganese
s. potassium
n. molybdenum
t. rubidium
o. nickel
p. nitrogen
u. sodium
f. chloride
1. magnesium
v. sulfur
q. oxygen w. zinc

Avg correct responses (\%)

\begin{tabular}{lllll}
\hline $\mathrm{N}^{\mathrm{y}}$ & Time 1 & Time 2 & Time 3 & Time 4 \\
\hline
\end{tabular}

$33 \quad 73$ NS 76 NS 76 NS 88 NS

$33 \quad 36 b^{x} \quad 61 \mathrm{ab} \quad 70 \mathrm{a} \quad 52 \mathrm{ab}$

88 NS

85 NS

$91 \mathrm{NS}$

$91 \mathrm{NS}$

${ }^{\mathrm{Z}} \mathrm{Oasis}^{\circledast}{ }^{\circledR e d g e}{ }^{\circledast}$ Growing Medium (Smithers-Oasis North America, Kent, OH); $1 \mathrm{ppm}=1 \mathrm{mg} \cdot \mathrm{L}^{-1}$.

${ }^{{ }} \mathrm{N}=$ number of student responses from which an average was obtained for each of the time periods.

xDifferent letters within each row indicate that means are significantly different based on multiple comparisons at $\alpha=0.05$ using the Bonferroni adjustment. 
Table 3. Average percent correct HORT 570 Greenhouse Operations Management student responses to seven higher-order learning (HOL) multiple choice questions concerning hydroponic production and general plant nutrition over four time periods: Time 1 [before mentioning plant nutrition, hydroponics, or recirculating solution culture during the course (11 Sept. 2013)], Time 2 [after the plant nutrition lectures were delivered but before the initiation of the module (2 Oct. 2013)], Time 3 [immediately upon completion of the module (13 Nov. 2013)], and Time 4 [at the end of the semester during the final examination (20 Dec. 2013)]. Correct answers to each question are in bold.

HOL knowledge question ${ }^{z}$

1) $\mathrm{pH}$ of the recirculating solution in a hydroponics lettuce production system has been measured as 7.9. What action will you take? (Circle one)

a. Add a dilute base to adjust $\mathrm{pH}$

b. Add a dilute acid to adjust $\mathrm{pH}$

c. Do nothing, because this $\mathrm{pH}$ is fine for optimal lettuce growth

2) A pour through extraction is conducted on pots of basil growing in a recirculating system.

The electrical conductivity (EC) reading is $4.5 \mathrm{dS} \cdot \mathrm{m}^{-1}$. The grower should: (Circle one)

a. Leach the pots with clear water

b. Increase the concentration of fertilizer in the recirculating solution

c. Do nothing, because this EC reading is fine for optimal basil growth

3) Irrigation water with a $\mathrm{pH}$ of greater than 9.0: (Circle one)

a. is definitely not usable to irrigate greenhouse crops and produce high quality

plant growth

b. can be used to irrigate greenhouse crops only if an acid is added to it

c. can be used to irrigate greenhouse crops only if a base is added to it

d. may be fine to use to irrigate greenhouse crops with no adjustment because the

$\mathrm{pH}$ of the irrigation water is not what directly influences the $\mathrm{pH}$ of the root medium

4) A hydroponic tomato (Solanum lycopersicum) operation has switched from growing tomatoes in root medium to rockwool slabs. The grower is beginning to see some symptoms of interveinal chlorosis of the lowest leaves. The fertilizer program provides $200 \mathrm{ppm}$ nitrogen

(N) from 20-10-20, which is made from ammonium nitrate, ammonium phosphate, and potassium nitrate, and has been adjusted to include an appropriate rate of every micronutrient. The irrigation water source is very pure rainwater. What is the problem? (Circle one)
a. Iron deficiency
e. Iron toxicity
b. Sulfur deficiency
c. Magnesium deficiency
d. Nitrogen deficiency
f. Sulfur toxicity
g. Magnesium toxicity
h. Nitrogen toxicity

5-A) You have a crop of marigold (Tagetes erecta) bedding plants that is half-way through the production cycle. Small dotted lesions are occurring on the oldest and midcanopy foliage. This crop has been fertilized with 100 ppm N from 20-10-20 general purpose fertilizer containing micronutrients and supplemented with $50 \mathrm{ppm}$ from

ammonium sulfate. The crop is growing in a commercial soilless root medium that was

amended pre-plant with all essential nutrients. What is the nutritional disorder?

(Circle one)

Irrigation Water

\section{Root Medium}

pH: 7.2

EC (mmho/cm): 0.4

Alkalinity (meq/L): 0.2

pH: 4.9

EC $(\mathrm{mmho} / \mathrm{cm}): 2.6$ phosphorus: $0.5 \%(\mathrm{O})$ Manganese: $610 \mathrm{ppm}(\mathrm{H})$

$\mathrm{N}$ (ppm): 120
a. Iron deficiency
b. Sulfur deficiency
c. Magnesium deficiency
d. Nitrogen deficiency

5-B) What is the cause? (Circle one)

a. The irrigation water $\mathrm{pH}$ is too high.

b. The irrigation water $\mathrm{pH}$ is too low.

c. The irrigation water EC is too high.

$\mathrm{d}$. The irrigation water EC is too low.
Tissue Analysis ( $\mathrm{O}=$ optimum,

$$
\mathrm{L}=\text { low, } \mathrm{H}=\text { high })
$$

nitrogen: 4\%(O) Iron: $1990 \mathrm{ppm}(\mathrm{H})$

$32 \quad 3$ NS 3 NS 6 NS 3 NS

2756 NS 48 NS 52 Ns 74 NS
$33 \quad 21$ c $\quad 39$ bc $\quad 82$ a $\quad 67 \mathrm{ab}$

$\begin{array}{lllll}32 & 6 \mathrm{~b} & 3 \mathrm{~b} & 38 \mathrm{a} & 63 \mathrm{a}\end{array}$

potassium: $4.1 \%(\mathrm{O})$ Zinc: $150 \mathrm{ppm}(\mathrm{H})$

magnesium: $0.3 \%(\mathrm{O})$ Copper: $113 \mathrm{ppm}(\mathrm{H})$

sulfur: $0.3 \%(\mathrm{O}) \quad$ Boron: $50 \mathrm{ppm}(\mathrm{O})$

e. Iron toxicity

f. Sulfur toxicity

g. Magnesium toxicity

h. Nitrogen toxicity

e. The root medium $\mathrm{pH}$ is too high.

f. The root medium $\mathrm{pH}$ is too low.

$\mathrm{g}$. The rate of N-P-K applied is too high.

h. The rate of N-P-K applied is too low. $\begin{array}{lllll}27 & 26 \mathrm{~b} & 11 \mathrm{~b} & 37 \mathrm{ab} & 59 \mathrm{a}\end{array}$ 
Table 3. (Continued) Average percent correct HORT 570 Greenhouse Operations Management student responses to seven higher-order learning (HOL) multiple choice questions concerning hydroponic production and general plant nutrition over four time periods: Time 1 [before mentioning plant nutrition, hydroponics, or recirculating solution culture during the course (11 Sept. 2013)], Time 2 [after the plant nutrition lectures were delivered but before the initiation of the module ( 2 Oct. 2013)], Time 3 [immediately upon completion of the module (13 Nov. 2013)], and Time 4 [at the end of the semester during the final examination (20 Dec. 2013)]. Correct answers to each question are in bold.

\begin{tabular}{|c|c|c|c|c|c|}
\hline \multirow[b]{2}{*}{ HOL knowledge question ${ }^{\mathrm{z}}$} & \multicolumn{5}{|c|}{ Avg correct responses (\%) } \\
\hline & & $\begin{array}{c}\text { Time } \\
1\end{array}$ & $\begin{array}{c}\text { Time } \\
2\end{array}$ & $\begin{array}{c}\text { Time } \\
3\end{array}$ & $\begin{array}{c}\text { Time } \\
4\end{array}$ \\
\hline $\begin{array}{l}\text { 5-C) What preventative strategy do you recommend so that this problem does not } \\
\text { occur in the future? } \\
\text { a. Inject acid into the irrigation water. } \\
\text { b. Increase the amount of sulfur and magnesium supplied in the soluble fertilizer program. } \\
\text { c. Increase the amount of dolomitic lime added to the root medium before planting. } \\
\text { d. Change the ammonium sulfate to potassium nitrate. } \\
\text { e. Increase the rate of nitrogen fertilizer applied. } \\
\text { f. Both b and c } \\
\text { g. Both c and d } \\
\text { h. Both b and d }\end{array}$ & 27 & $19 a b^{x}$ & $11 \mathrm{~b}$ & $30 \mathrm{ab}$ & $48 \mathrm{a}$ \\
\hline
\end{tabular}

${ }^{\mathrm{z}} \mathrm{l} \mathrm{dS} \cdot \mathrm{m}^{-1}=1 \mathrm{mmho} / \mathrm{cm}, \mathrm{l} \mathrm{ppm}=1 \mathrm{mg} \cdot \mathrm{L}^{-1}, 1 \mathrm{me}(\mathrm{meq} / \mathrm{L})=1 \mathrm{mmol} \cdot \mathrm{L}^{-1}$

${ }^{y} \mathrm{~N}=$ number of student responses from which an average was obtained for each of the time periods.

${ }^{x}$ Different letters within each row indicate that means are significantly different based on multiple comparisons at $\alpha=0.05$ using the Bonferroni adjustment.

criteria had to be met: 1 ) the student must have completed the survey at each of the four time intervals and 2) the student must have answered every question for the questions associated with a given index. Data from students that did not meet these two criteria within the given section were removed from the index analyses. Student responses were subjected to within-subjects analysis of variance using SPSS (version 17.0; IBM Corp., Armonk, NY). Multiple comparisons between each time period were conducted using the Bonferroni adjustment.

\section{Results and discussion}

Perception Questions. Student confidence with crop production in recirculating culture only increased upon completion of the module at Time 3 (Table 1, Item 2). This response shows that students became more comfortable with the idea of managing a hydroponic system after hands-on experience was gained. At the onset of the course (Times 1 and $2)$, student confidence was higher $(P<0.001)$ regarding management of potted crop production (Table 1 , Item 1) vs. hydroponic production (Table 1, Item 2). However, after the completion of the hydroponics module (Time 3$)$, no difference $(P=$ 0.183 ) between student confidence of these management systems was observed. This finding displays a gain in student confidence regarding hydroponic production that matched student confidence in potted crop production. Thus, the hydroponics module was essential for instilling confidence in students regarding the management of hydroponics production. These findings were similar to those of Lavis and Brannon (2010) who studied an experiential learning module in a landscape irrigation undergraduate course. They found student participation in a specific laboratory activity led to higher levels of confidence regarding the student performing the given task on their own (Lavis and Brannon, 2010). Similarly, in a study-abroad trip to Honduras, Snyder et al. (2012) found that student confidence in answering questions regarding water relations increased after engaging in experiential learning activities. Likewise, we found that student confidence related to managing a hydroponic system only significantly increased after having the hands-on experience provided by the module.

Additionally, an improved understanding of the pros and cons surrounding organic and conventional nutrient management programs was achieved from this module. This result was apparent as student confidence regarding these principles increased from Time 2 to Time 3 (Table 1, Items 3 and 4). These results not only included an increase in the students' understanding of the consequences and benefits from each fertilization method (Table 1, Item 3) but also an increase in the knowledge of how the end product for the consumer was affected (Table 1, Item 4). As differences in student confidence for these nutrition questions were only observed upon completion of the module at Time 3, hands-on experience with nutrition management in recirculating solution culture was essential to significantly increase student assurance regarding these concepts. Student perceptions concerning hydroponics as an effective alternative to traditional production systems and the benefit to their future career remained constant across all time intervals (Table 1, Items 5 and 6). These findings show that while the students were not well aware of the management and principles underlying hydroponic production at the module onset, they understood the importance and value that such knowledge may have in their future careers. Lastly, no differences between Times 3 and 4 were observed for any of the perception questions (Table 1 ). Thus, student perceptions were retained for the remainder of the course, suggesting the experiential module aided in solidifying student confidence regarding the concepts listed.

LOL KNOWLEDGE QUESTIONS. For many of the basic LOL questions, lecture material was sufficient for student performance. This result is supported by analysis of responses to the question regarding the essential plant nutrients, solely targeting a student's ability to memorize important 
information. In the case of this question, an increase in student performance was only apparent between Time 1 and 2 (Table 2, Item 8). This same response was also seen in LOL questions 5 and 7 (Table 2, Items 5 and 7). An increase in LOL from Time 2 to 3 was also apparent with question 4 (Table 2, Item 4). With this question directly involving hydroponic production, an increase was expected as students became more comfortable with hydroponics terminology and maintenance after performing these tasks firsthand over multiple weeks. A similar result was found in research conducted by Bauerle and Park (2012) regarding a tree climbing exercise incorporated into an introductory level plant science course. These authors found that students who performed a hands-on tree climbing exercise scored significantly higher on the related homework assignment than those who did not participate. Overall, students also scored higher on the homework assignment where experiential learning was incorporated compared with assignments where it was not (Bauerle and Park, 2012).

Additionally, the LOL index scores significantly increased from Time 1 to 2 and also from Time 2 to 3 (Fig. 1). This finding further suggests that the lecture material presented before Time 2 assisted in significantly raising student scores overall. Additionally, the increase from Time 2 to 3 displays that the module was beneficial in further solidifying many of these basic LOL concepts, ultimately resulting in significantly increased student scores at Time 3 . Thus, while a positive impact on student performance regarding LOL questions was apparent after the lecture material was presented, the experiential module did assist in further increasing the overall LOL index scores as well as performance on some hydroponics-based questions. Therefore, a module based on crop production in recirculating culture can effectively be used to supplement typical plant nutrition lectures and increase student overall LOL.

HOL KNOWLEDGE QUESTIONS. While student performance on LOL questions increased from Time 1 to 2 after the lecture material was presented, student performance on HOL questions did not (Fig. 1). Rather, student HOL index scores did not significantly increase until after the completion of the experiential module at Time 3 (Fig. 1). This response can be seen directly in HOL questions 2 and 3 (Table 3, Items 2 and 3 ), showing experiential learning had the most significant impact on HOL performance in the students.

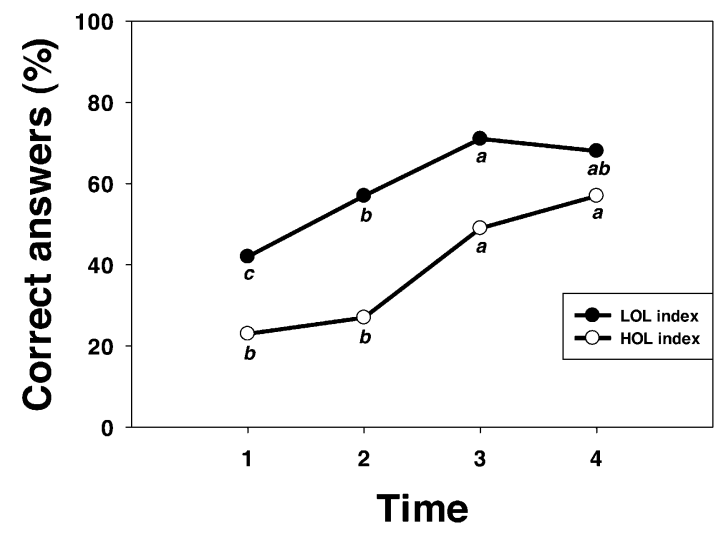

Fig. 1. Lower-order learning (LOL) and higher-order leaning (HOL) index (average correct answers from HORT 570 Greenhouse Operations Management student responses out of seven questions of each type) results over four time periods: Time 1 [before mentioning plant nutrition, hydroponics, or recirculating solution culture during the course (11 Sept. 2013)], Time 2 [after the plant nutrition lectures were delivered but before the initiation of the module (2 Oct. 2013)], Time 3 [immediately upon completion of the module (13 Nov. 2013)], and Time 4 [at the end of the semester during the final examination (20 Dec. 2013)]. LOL index $(N=31)$ includes questions $1-7$ from Table 2 . HOL index $(N=25)$ includes questions 1 to 7 from Table 3. Different letters within each index indicate that means are significantly different based on multiple comparisons at $\alpha=0.05$ using the Bonferroni adjustment.
Additionally, student performance significantly increased from Time 1 to 2 as well as from Time 2 to 3 for HOL question 1 , which was directly targeted toward hydroponic production (Table 3, Item 1 ). This finding is similar to what was observed in LOL question 4 (Table 2, Item 4). While students were equipped with the necessary knowledge from the lecture material of the course to improve performance on this question at Time 2 , they became more confident and familiar with production in recirculating culture over the course of the module to further increase performance at Time 3. Thus, these results provide evidence that experiential learning improves student understanding and fosters HOL.

However, HOL question 5 produced an interesting contradiction during the course of the study (Table 3 , Items $5 \mathrm{~A}-\mathrm{C}$ ). This question was structured as a short case study and required the students to use critical thinking skills to diagnose a nutritional disorder and give recommendations to remedy it. We found that many students may have initially become overwhelmed or felt pressed for time upon reaching this question in the instrument, and many times skipped the question entirely. Ultimately, this resulted in fewer total responses for this group of questions, which may have attributed to the lack of significance generally observed across Times 1 through 4. Additionally, the nonsignificant increase in scores at Time 4 was possibly due to students' becoming more comfortable with the subject matter as the questions were repeated over time (Table 3; Items 5A-C). Regardless, because students did not clearly demonstrate improved response to these questions, our study does not provide clear evidence that the module improved student mastery of HOL general plant nutrient management content not specific to crop production in solution culture.

No differences were observed from Time 3 to 4 for any LOL question (Table 2), HOL question (Table 3), or LOL and HOL index (Fig. 1). Thus, students retained the knowledge learned throughout the course of the study, and student familiarity with the questions in the assessment instrument did not pose any significant increases in average scores. 


\section{Conclusions}

The experiential module with crops produced in recirculating solution culture significantly improved student confidence with regard to system management. Specific to horticulture as an academic major, experiences such as this are valuable in increasing students' confidence and equipping them to deal with scenarios involving recirculating solution culture in their future careers. Additionally, the students found value in these experiences, as shown in the results of the perception questions of the assessment. It is important these modules not only cater to knowledge deemed essential for future success by the instructor but also include information and activities that are of interest and value to the students. With the significant increase observed in HOL only upon completion of the experiential module, the benefit and necessity of experiential learning opportunities becomes evident, despite the time, cost, and organizational challenges that must be dealt with to accomplish their implementation. While traditional lecture coverage of content is sufficient to accomplish many aspects of LOL, these results support that attainment of HOL is augmented by purposefully designed experiential learning.

\section{Literature cited}

Bauerle, T.L. and T.D. Park. 2012. Experiential learning enhances student knowledge retention in the plant sciences. HortTechnology 22:715-718.

Cannon, H.M. and A.H. Feinstein. 2005. Bloom beyond bloom: Using the revised taxonomy to develop experiential learning strategies. Dev. Business Simulations Experiential Learning 32:348-356.

Dimitri, C. and C. Greene. 2012. Recent growth patterns in the U.S. organic foods market. USDA Economic Research Service. 8 Aug. 2014. <http://www.ers.usda.gov/ publications /aib-agricultural-informationbulletin/aib777.aspx\#.U-aFumOTLyA > .

Kolb, D.A. 1984. Experiential learning: Experience as the source of learning and development. Prentice-Hall, Upper Saddle River, NJ.

Krathwohl, D.R. 2002. A revision of Bloom's taxonomy: An overview. Theory Pract. 41:212-218.

Lamba, B. and G. Chapman. 2010. Teaching sustainable design: A hands-on interdisciplinary model. Hort Technology 20:487-494.

Lavis, C.C. and L.A. Brannon. 2010. An experiential learning activity in a landscape irrigation undergraduate course. HortTechnology 20:467-474.

Snyder, L.U., M.V. Mickelbart, and V. Eylands. 2012. Students' experiential learning of hydroponics and local markets on the island of Roatán, Honduras. J. Intl. Agr. Ext. Educ. 19:54-63.

Stearns, D.T. 1995. On-site instruction for landscape contracting students. HortTechnology 5:78-80. 